\title{
EL COHECHO COMO PROPUESTA O ACEPTACIÓN DE UNA DONACIÓN REMUNERATORIA*
}

[Bribery as proposal or acceptance of a remunerative donation]

\author{
Juan Pablo Mañalich Raffo** \\ Universidad de Chile
}

\section{RESUMEN}

La dogmática del cohecho suele recurrir a la noción de un pacto ilícito, a cuya celebración se orientaría el comportamiento del funcionario, y que exhibiría la forma de un (pseudo-)contrato sinalagmático. Aquí se defenderá

\section{ABSTRACT}

The dogmatic of bribery usually resorted to the notion of an illicit agreement, whose conclusion would guide the behavior of the official, and that would exhibit the form of a (pseudo-) synalagmatic contract. Here, the superiority of

Recibido el 18 de mayo de 2018 y Aprobado el 23 de agosto de 2018

* Sendas versiones preliminares del presente trabajo fueron presentadas en las XII Jornadas Patagónicas de Derecho Penal, organizadas por la Fiscalía Regional de Aysén y celebradas los días 22 y 23 de marzo de 2018, y en la sesión del Coloquio de Derecho Penal Económico, organizado por el Programa de Derecho Penal de la Universidad Diego Portales, celebrada el 24 de abril de 2018. Agradezco a los participantes en ambos foros de discusión por las observaciones dirigidas a los argumentos aquí desarrollados. Puesto que la versión definitiva del texto principal quedó fijada el 13 de agosto de 2018, las modificaciones experimentadas por la regulación del cohecho y el soborno, plasmadas en la Ley 21.121, publicada en el Diario Oficial con fecha 20 de noviembre del mismo ańo, no pudieron ser consideradas.

** Abogado, Universidad de Chile. Doctor en Derecho, Universidad de Bonn, Alemania. Profesor de Derecho Penal en la Universidad de Chile. Correo electrónico: jpmanalich@derecho.uchile.cl. 
la superioridad del modelo alternativo de la "donación remuneratoria", sobre cuya base se esclarecerá la relación que debe darse entre el beneficio solicitado o aceptado y la ejecución u omisión de una acción conectada con el cargo, así como el grado de determinación con el cual debería quedar especificado tal "servicio funcionarial".

\section{Palabras clave}

Derecho Penal - cohecho - donación remuneratoria - función pública - corrupción. the alternative model of "remunerative donation" will be defended, based on which the relationship between the requested or accepted benefit and the execution or omission of an action connected with the position, as well as the level of determination which should be specified such "official service".

\section{KEYWORDS}

Criminal Law - bribery - remunerative donation - public function - corruption.

\begin{abstract}
"Los preceptistas Luis de Granada y Bernard Lamy se acuerdan en aseverar que el origen de la metáfora fue la indigencia del idioma. La traslación de los vocablos se inventó por pobreza y se frecuentó por gusto, arbitra el primero. La lengua más abundante se manifiesta alguna vez infructuosa y necesita de metáforas, corrobora el segundo".

Borges, "Examen de metáforas".
\end{abstract}

\title{
I. LA ESTRUCTURA TíPICA DEL COHECHO BAJO LA METÁFORA CONTRACTUAL
}

El cohecho constituye el paradigma de un delito de corrupción ${ }^{1}$. Esto nada dice, sin embargo, acerca del bien jurídico específicamente menoscabado por un comportamiento típicamente relevante a ese título. Pues el concepto de corrupción no designa la afectación de un bien jurídico determinado, sino más bien un determinado modo de ataque a algún bien jurídico, siendo la identificación de éste conceptualmente independiente de la mención de ese mismo modo de ataque ${ }^{2}$. En estos términos,

${ }^{1}$ La especificación del concepto de corrupción que se ofrece en lo que sigue ha sido ya presentada en Mañalich, Juan Pablo, La negociación incompatible como delito de corrupción, en Revista de Estudios de la Justicia 23 (2015), pp. 94 ss. Véase también ArtazA, Osvaldo, La utilidad del concepto de corrupción de cara a la delimitación de la conducta típica en los delitos de cohecho, en Politica Criminal 11 (2016), 21, pp. 316 ss.

2 KIndhäUser, Urs, Presupuestos de la corrupción punible en el Estado, la economía y la sociedad. Los delitos de corrupción en el Código penal alemán, en Politica Criminal 2 (2007), 3, p. 2. Para una recepción de este punto de vista en la discusión chilena, véase por ejemplo Carnevali, Raúl - Artaza, Osvaldo, La naturaleza plu- 
por "corrupción" es posible entender una "vinculación contraria a intereses de una ventaja con el ejercicio de un poder de decisión transferido" 3 . Esto quiere decir que la existencia de una situación de corrupción presupone, en primer lugar, que una persona esté habilitada para ejercer algún poder de decisión en interés de otro(s); en segundo lugar, que el ejercicio de ese poder de decisión quede vinculado a la obtención de una ventaja indebida; y en tercer lugar, que el carácter indebido de esa ventaja se funde en la incompatibilidad entre la obtención de esa ventaja y la promoción del interés al que ha de servir el ejercicio del poder de decisión en cuestión ${ }^{4}$.

Aquí interesa un ámbito particular en el cual la posibilidad de corrupción, en cuanto "modo de ataque", se presenta como especialmente amenazante, a saber: el ámbito en el cual el ejercicio del respectivo poder de decisión se corresponde con el desempeño de una función pública. Pues ello se traduce en que el ejercicio de ese poder de decisión ha de quedar legitimado por su contribución a la realización de una determinada finalidad pública, de manera tal que la vinculación de una ventaja inconexa con el ejercicio de ese poder de decisión tenga la potencialidad de comprometer la realización de esa misma finalidad. En tal medida, la corrupción en el desempeño de una función pública afecta el contenido nuclear del principio de probidad administrativa, consistente en la exigencia de que la respectiva función sea ejercida dando "preeminencia [al] interés general sobre el interés particular", tal como lo establece el inc. $2^{\circ}$ del art. 52 de la Ley 18.575, Orgánica Constitucional de Bases Generales de Administración del Estado.

De las concreciones del principio de probidad que se encuentran especificadas en el art. 53 de la misma Ley 18.575, la exigencia de imparcialidad en el ejercicio de la función pública resulta distintivamente puesta en cuestión por toda instancia de corrupción en el sentido recién precisado. Desde este punto de vista, lo distintivo del cohecho en cuanto delito de corrupción consiste en que la ventaja indebidamente asociada al ejercicio de la función pública es solicitada de, u ofrecida por, alguna otra persona $a^{5}$ que en tal medida viene en consideración como potencial

riofensiva y transnacional del fenómeno de la corrupción. Desafios para el Derecho Penal, en Ius et Praxis 22 (2016), 2, pp. 54 ss.

${ }^{3}$ Kindhäuser, Urs, Presupuestos..., cit. (n. 2), p. 6.

${ }^{4}$ En detalle Kindhäuser, Urs, Presupuestos..., cit. (n. 2), pp. 4 ss.; coincidentemente Artaza, Osvaldo, cit. (n. 1), pp. 316 ss. Para una concepción del todo próxima, anclada a la comprensión del cohecho como un "delito de deslealtad", véase Green, Stuart, Lying, Cheating, and Stealing (Oxford y Nueva York, Oxford University Press, 2006), pp. 203 ss.

5 Kindhäuser, Urs, Presupuestos..., cit. (n. 2), pp. 7 ss. En general sobre la estructura típica del cohecho bajo el derecho penal chileno, véase Oliver, Guillermo, 
sobornador. Esto último suele ser esclarecido en términos de lo que cabe denominar la "metáfora contractual", tomada como clave de reconstrucción dogmática de la estructura típica del cohecho. Ello haría posible dar cuenta de la estructura típica del cohecho a través de un recurso a la noción de un "contrato" -el cual obviamente adolecería de "objeto ilícito"- a cuya "celebración" se orientaría el comportamiento de las dos "partes" que vienen en consideración, a saber: la persona del funcionario público eventualmente sobornado, como posible "vendedor" de un servicio vinculado al desempeño de su función, y la persona del eventual sobornador, como posible "comprador"'. Y la "venta" en cuestión, en caso de llegar a "perfeccionarse", habría de encontrarse referida a una "prestación" consistente en la ejecución o la omisión de un acto institucionalmente conectado con el ejercicio de la función pública desempeñada por el primero, frente a lo cual el beneficio a ser recibido (por el funcionario) de parte del eventual sobornador representa el correspondiente "precio". Con ello, el contrato en cuestión aparecería proyectado como uno cuya naturaleza correspondería a la de una "venta de servicio".

Tal reconstrucción de la estructura típica del cohecho tiene su contexto más natural en la tradicional caracterización del cohecho como un delito de encuentro ("bilateral")

Aproximación al delito de cohecho, en Revista de Estudios de la Justicia 5 (2004), pp. 88 ss., 96 ss.

${ }^{6}$ Para semejante aproximación, véase ya Carrara, Francesco, Programa de Derecho Criminal. Parte Especial (Bogotá, Temis, 1961), V, pp. 94 ss., 101 ss.; también Binding, Karl, Lehrbuch des Gemeinen Deutschen Strafrechts (Léipzig, Félix Meiner, 1905), II, pp. 712 ss. Más recientemente, y dando cuenta del estatus del concepto de cohecho como "forma del pensamiento jurídico", Guzmán Dalbora, José Luis, Colectánea Criminal. Estampas de la parte especial del derecho penal (Buenos Aires y Montevideo, BdF, 2017), pp. 163 ss., 166 ss. En el contexto de la discusión angloamericana, una caracterización del cohecho (bribery) como delito estructurado sobre la base de un acuerdo entre dos partes es ofrecida en Green, Stuart, cit. (n. 4), pp. 197 ss., 202 ss.

7 Como es obvio, la noción de venta así empleada no admite ser identificada con la acepción estricta que la expresión "venta" exhibe cuando se habla del contrato de compraventa, en cuanto contrato fundante, para el vendedor, de una obligación referida a una cosa corporal. Que el verbo "vender" conoce usos considerablemente más laxos lo muestra el hecho, aquí significativo, de que una de sus acepciones lexicográficas consista, justamente, en "dejarse sobornar".

${ }^{8}$ Véase sólo Labatut, Gustavo, Derecho Penal (7a edición, Santiago, Editorial Jurídica de Chile, 2005), II, p. 90. Que semejante caracterización no supone, empero, asumir que sobornado y sobornador serían co-intervinientes en un mis mo delito, fue muy claramente advertido ya por Beling, Ernst, Die Lehre vom Verbrechen (Tubinga, J.C.B. Mohr [Paul Siebeck], 1906), pp. 272 ss. 
vigente vuelve implausible esta última caracterización, precisamente por la configuración autónoma del injusto típico del cohecho, por un lado, y del soborno, por otro. Esto concierne directamente a la determinación de sus respectivas condiciones de consumación, que todavía se encuentran recíprocamente configuradas. En referencia al beneficio constitutivo de la ventaja indebida, la "solicitud de recibir" por parte del funcionario se corresponde con el "consentimiento en dar" por parte del potencial sobornador, mientras la "aceptación de recibir" por parte del funcionario se corresponde con el "ofrecimiento en dar" por parte del potencial sobornador. Notablemente, en tal correlación de las dos modalidades que pueden asumir, respectivamente, el cohecho y el soborno, todavía parece exhibir alguna vigencia la apelación a la estructura de un delito de encuentro. Para comprobar esto basta con considerar los presupuestos de la modalidad de cohecho consistente en la "aceptación de recibir" por parte del funcionario: conceptualmente, el funcionario no puede aceptar recibir (algo) a menos que otra persona le haya ofrecido dar (algo). Y lo mismo sucede, mutatis mutandis, tratándose de la modalidad de soborno consistente en el "consentimiento en dar" por parte del potencial sobornador: conceptualmente, una persona no puede consentir en dar (algo) a menos que otra -aquí: el funcionario- haya solicitado recibir (algo).

Lo anterior no es casualidad. En uno y otro caso, se trata de modalidades típicas definidas por la circunstancia de que el autor del respectivo delito aparece, en términos de la metáfora contractual, ocupando la posición de aceptante frente a una oferta ajena. Y por definición, la posibilidad de aceptar una oferta presupone la existencia de esa oferta. Pero esto basta para advertir, a contrario sensu, por qué resultan problemáticas, desde el punto de vista de la tesis del delito de encuentro, las otras dos constelaciones, esto es, la de cohecho en la cual el funcionario solicita (recibir) y la de soborno en la cual la otra persona ofrece (dar). Pues aquí quien realiza la respectiva modalidad típica aparece ocupando, también en términos de la metáfora contractual, la posición de oferente. Y la posición de oferente, si bien presupone la existencia de un destinatario de la oferta, no depende de que este último efectivamente se convierta en aceptante. Así, es claro que el solo hecho de que un funcionario solicite a alguna persona que ésta le haga llegar una suma de dinero a cambio de la ejecución de un acto propio del cargo del primero bastará para que se configure un cohecho imputable al funcionario, sin que eso suponga que la otra persona en efecto llegue a consentir en efectuar ese traspaso de dinero. Y al revés, es claro también que el solo hecho de que alguna persona ofrezca hacer llegar una suma de dinero a un funcionario a cambio de la ejecución, por parte de éste, de un acto propio de su cargo, bastará para que aquella persona se convierta en 
autora de soborno, sin que eso suponga que el funcionario en efecto haya llegado a aceptar recibir la suma que le fuera ofrecida.

Con ello, la tesis del delito de encuentro carece de rendimiento explicativo para dar cuenta del conjunto de las modalidades de cohecho y soborno tipificadas en los arts. 248 y siguientes del Código Penal chileno. Pero esto no quiere decir que, con ello, semejante concepción pierda toda relevancia interpretativa. Pues para entender en qué consiste, en cada caso, la respectiva forma de comportamiento con relevancia típica a título de cohecho o soborno, sigue siendo imprescindible tener en cuenta el carácter interdependiente de las posiciones del funcionario y del eventual sobornador: lo que uno u otro hace ha de ser juzgado en atención al significado de su comportamiento en referencia al acuerdo de voluntades que se pretende alcanzar con la otra persona, a pesar de que dicho acuerdo de voluntades no necesite llegar a producirse para los efectos de la consumación del hecho (individual) eventualmente imputable a uno u otro, según corresponda.

\section{EL MODELO DE LA DONACIÓN REMUNERATORIA}

Las disquisiciones precedentes no bastan para tener por demostrado el rendimiento de la metáfora contractual como clave interpretativa de los arts. 248 y siguientes del CP. A este respecto, el problema fundamental consiste en esclarecer la naturaleza de la conexión típica que ha de constituirse entre el beneficio que el funcionario ha de solicitar o aceptar, por un lado, y la realización, pretérita o futura, de un comportamiento consistente o bien en la ejecución de un acto "propio de su cargo" (en los términos del art. 248), o bien en la omisión de "un acto debido propio de su cargo" o la ejecución de "un acto con infracción de los deberes del cargo" (en los términos del art. 248 bis), o bien en la perpetración de un hecho punible tipificado bajo el párr. $4^{\circ}$ del Título III o bajo el Título V del Libro II del CP (en los términos del art. 249), por otro9. Para simplificar el análisis, en lo que sigue se empleará la expresión "servicio funcionarial" para designar, genéricamente, cualquiera de las tres configuraciones que puede mostrar el comportamiento cuya realización sería potencialmente "vendida" por el funcionario.

En lo que aquí interesa, la metáfora contractual tiende a favorecer la representación de que entre el beneficio solicitado o aceptado y el servicio funcionarial tendría que darse una conexión sinalagmática. Esto encuentra

9 Véase al respecto Hernández, Héctor, La inconveniente exigencia de un acto funcionario determinado como contraprestación en el delito de cohecho, en Revista de Ciencias Penales 43 (2016), 4, pp. 16 ss. 
una formulación suficientemente precisa en la noción de "pacto ilícito" (Unrechtsvereinbarung), a través de la cual la doctrina y la jurisprudencia alemanas tematizan, en referencia a la estructura típica de los delitos de corrupción en el ejercicio de la función pública, la equivalencia conmutativa que, en el marco de la interacción entre las dos partes del potencial intercambio, habría de darse entre el servicio funcionarial, por un lado, y el beneficio solicitado o aceptado por el funcionario, por otro ${ }^{10}$. Esto último se ve decisivamente relativizado, sin embargo, mediante la precisión de que esa equivalencia tendría que ser entendida en el sentido de que el beneficio solicitado o aceptado por el funcionario tiene que representar el "contravalor" (Gegenwert) del servicio funcionarial en tal medida "vendido", sin que, a la inversa, el servicio funcionarial deba ser entendido como el "contravalor" del beneficio solicitado o aceptado. Esto determina que la "relación de referencia" entre el servicio funcionarial y el beneficio correlativo resulte ser asimétrica: sólo el beneficio necesita venir en consideración como contraprestación por el servicio funcionarial de que se trate, sin que éste, por su parte, tenga que ser entendido como una contraprestación por el beneficio ${ }^{11}$. Esto explica, por ejemplo, que -ya bajo el art. $248 \mathrm{del} \mathrm{CP-} \mathrm{no} \mathrm{constituya} \mathrm{cohecho} \mathrm{el} \mathrm{ofrecimiento,} \mathrm{por} \mathrm{parte}$ del funcionario, de la ejecución de algún acto propio de su cargo que, "en reciprocidad" o por gratitud, un funcionario público pudiera hacer a alguna persona que, unilateralmente y sin conexión con la solicitud de la ejecución de semejante acto, le hubiera hecho llegar un obsequio (aun de alta significación pecuniaria). Pues en este último caso es claro que la previa realización del obsequio no podría ser entendida como el pago de un "precio" por la posterior realización, igualmente unilateral o gratuita, del servicio funcionarial.

En los términos de la metáfora contractual, lo anterior quiere decir que el beneficio solicitado o aceptado por el funcionario debe aparecer teniendo como causa, en el sentido de la correspondiente noción obligacional ${ }^{12}$, la

${ }_{10}$ Véase por todos KindhäUser, Urs, LPK-StGB (4a edición, Baden-Baden, Nomos, 2010), $\$ 331$, n.m. 19, 82 ss.; KuHlen, Lothar, 331, en KIndHäUser, Urs - Neumann, Ulfrid - Paeffgen, Hans-Jörg (coords.), NK-StGB (5a edición, Baden-Baden, Nomos, 2017), $\$ 331$, n.m. 17.

${ }^{11}$ Kuhlen, Lothar, cit. (n. 10), $\$ 331$, n.m. 93.

12 Como observara Claro Solar, Luis, Explicaciones de derecho civil chileno y comparado (Santiago, Editorial Jurídica de Chile, 1979), V, pp. 304 ss., tal noción de causa debe ser definida en el sentido de una "causa final", diferenciada de la correspondiente "causa eficiente". Que, así entendida, tal noción de causa haya sido ajena al derecho privado romano, como lo intentara demostrar GuZMÁN BRITo, Alejandro, Derecho Privado Romano (Santiago, Editorial Jurídica de Chile, 1996), I, pp. 718 ss., no es algo que sea pertinente considerar aquí. 
realización pretérita o futura del respectivo servicio funcionarial, sin que, al revés, el servicio funcionarial en cuestión, en caso de llegar a materializarse, hubiera de tener como causa, en el mismo sentido, la obtención del beneficio solicitado o aceptado. Pero si esto es correcto, de ello se sigue, entonces, que el recurso a la metáfora contractual necesita ser drásticamente revisado en pos de la reconstrucción dogmática de la tipificación de las diferentes variantes de cohecho (así como, correlativamente, de las correspondientes variantes de soborno).

La inadecuación del modelo del contrato bilateral, favorecido por el recurso tradicional a la metáfora contractual, queda de manifiesto, desde ya, si se repara en cuán implausible resulta caracterizar la posición del funcionario que incurre en cohecho al solicitar o aceptar un beneficio a cambio del correspondiente servicio funcionarial, respectivamente, como la posición de un oferente o un aceptante en el marco de la preparación de un contrato pretendidamente sinalagmático, esto es, bilateral. Pues esto es imposible de compatibilizar, desde ya, con el hecho de que, bajo la regulación legal vigente, resulten típicamente relevantes tanto el cohecho antecedente como el cohecho subsiguiente. La primera de las dos formas viene en consideración cuando el beneficio es solicitado o aceptado para la (posterior) realización del servicio funcionarial; la segunda forma, como contrapartida, cuando el beneficio se solicita o acepta por la (previa) realización del servicio funcionarial. Esto muestra que, de lege lata, el núcleo típico del cohecho se encuentra reducido a la solicitud o la aceptación, por parte del funcionario, de un beneficio de cierta índole, como contraprestación por la realización, pretérita o futura, del respectivo servicio funcionarial, sin que esto pueda redefinirse en el sentido de la formulación o la aceptación de una oferta, por parte del funcionario, referida a que éste realice el servicio funcionarial. Pues tratándose de un posible cohecho subsiguiente, el servicio funcionarial en cuestión es tenido por ya realizado cuando el funcionario solicita o acepta recibir el beneficio en la forma de la correspondiente "contraprestación"13. Este sería el caso, por

${ }^{13}$ La precisión en cuanto a que el servicio en cuestión ha de ser presentado como ya prestado, sin que en efecto necesite haber sido prestado, para que se configure un eventual cohecho subsiguiente es importante desde el punto de vista de la pregunta de si, en caso de no haber sido efectivamente prestado, la solicitud o la aceptación del beneficio en cuestión, por parte del funcionario, pudiera exhibir relevancia típica también a título de estafa, en la medida en que el funcionario en efecto declare explícita o concluyentemente- haberlo prestado. Bajo una concepción del engaño eventualmente constitutivo de estafa, que condiciona la satisfacción del correspondiente elemento del tipo a que la declaración cuya falsedad es generativa del error bajo el cual ha de tener lugar la disposición patrimonialmente perjudicial se encuentre referida a circunstancias, con relevancia para la disposición, en relación con las 
ejemplo, si P, profesor de universidad estatal (y en tal medida funcionario público), solicitara o aceptara el ofrecimiento de una suma de dinero de parte del estudiante $\mathrm{E}$, en virtud de haber ya evaluado el examen final de la correspondiente asignatura con una nota aprobatoria.

Sería un error asumir, ahora bien, que la inadecuación del modelo del contrato bilateral es privativa del ámbito del cohecho subsiguiente. Pues considérese ahora la siguiente variación del caso recién ofrecido: $\mathrm{P}$ solicita a E la suma de $\$ 300.000$ pesos como contraprestación por calificar formalmente su examen con la mejor nota de la escala, en circunstancias de que, de acuerdo con la pauta objetiva de corrección, el examen en efecto amerita esa nota.

Bajo el modelo del contrato bilateral, lo natural sería sostener que, en este último caso, P aparecería como el emisor de una oferta condicional, consistente en el anuncio de la ejecución, por su parte, de la acción consistente en calificar el examen de $\mathrm{E}$ con la nota que a éste corresponde, a cambio de que $\mathrm{E}$ le provea una determinada suma de dinero. Pero esto desconoce que no es en absoluto obvio que la propuesta dirigida por $\mathrm{P} \mathrm{a}$ E deba ser caracterizada, en efecto, como una oferta condicional. Nótese, a este respecto, que esta última caracterización sólo resultaría unívoca si se asume que el acto de habla explícitamente realizado por P tendría el carácter de una "propuesta afectadora-de-preferencias", que en cuanto tal exhiba, pragmáticamente, una estructura implícitamente bicondicional ${ }^{14}$. Esto quiere decir que el acto de habla realizado por $\mathrm{P}$ tendría que poder ser interpretado como el anuncio explícito de que $\mathrm{P}$ calificará el examen de E con la nota debida, en caso de que E le haga llegar la correspondiente suma de dinero, acompañado del anuncio implícito de que P no calificará el examen de E con la nota debida, en caso de que E no le haga llegar la suma de dinero en cuestión. Pero si ésta es la interpretación pertinente

cuales la potencial víctima pueda reclamar una específica "pretensión de verdad" oponible al potencial estafador -véase en este sentido KindHÄUSER, Urs, 263, en Kindhäuser, Urs - Neumann, Ulfrid - Paeffgen, Hans-Jörg (coords.), NK-StGB ( 5 a edición, Baden-Baden, Nomos, 2017), $\$ 263$, n.m. 63 ss.-, es claro que en los casos aquí relevantes habría que negar la configuración de un engaño típicamente relevante. Pues el potencial sobornador no puede, con arreglo a las valoraciones jurídicas plasmadas en la ilicitud del soborno (y correlativamente del cohecho), pretender recibir información veraz acerca de la ejecución u omisión de una acción conectada con el desempeño del cargo o la función, por parte del funcionario público, para así efectuar una disposición consistente en "retribuir" o "remunerar" al funcionario por el servicio así prestado.

${ }^{14}$ Véase al respecto, y en detalle, Mañalich, Juan Pablo, El chantaje como coacción. Una reconstrucción lógica de la distinción entre amenazas y ofertas condicionales, en DOXA 41 (2018), en prensa. 
del acto de habla efectuado por $\mathrm{P}$, de ello se sigue que la correspondiente propuesta afectadora-de-preferencias no puede ser caracterizada como una oferta condicional, sino más bien como una amenaza condicional.

Esto último descansa en el hecho de que, en atención a la conjunción del anuncio condicional explícito y el anuncio condicional implícito, $\mathrm{P}$ aparece presentando a $\mathrm{E}$ la disyuntiva entre que $\mathrm{P}$ evalúe el examen de $\mathrm{E}$ con la nota debida y que $\mathrm{P}$ no lo evalúe con la nota debida. Y en la medida en que esa acción resulte jurídicamente requerida para $P$, esto es, en la medida en que, en cuanto profesor universitario, P esté obligado a calificar el examen de E con la nota que objetivamente le corresponde, entonces la presentación de esa disyuntiva se corresponde con la formulación de una amenaza que "respalda" la exigencia de la entrega de la respectiva suma de dinero que $\mathrm{P}$ dirige a $\mathrm{E}^{15}$.

Lo anterior muestra la inadecuación del modelo del contrato bilateral, que precisamente necesita asumir que la interacción "preparatoria" del correspondiente pacto ilícito tendría que conllevar la formulación de una oferta condicional, sea por parte del potencial autor de cohecho, sea por parte del potencial autor de soborno, según corresponda. Y esto se ve radicalmente desafiado por la constatación de que, en los casos en los cuales el comportamiento del primero puede ser identificado con la solicitud de algún beneficio "a cambio de" la ejecución futura de una acción que le está jurídicamente requerida en razón de su cargo, la propuesta implícitamente bicondicional formulada por el funcionario tiene el carácter de una amenaza condicional. Tal amenaza condicional podría resultar punible sin más bajo el art. 296 o el art. 297 del CP, según si el anuncio de la omisión de la acción requerida se corresponda o no con el anuncio de un mal constitutivo de delito (omisivo). Que ese mismo comportamiento del funcionario pueda resultar, no obstante ello, constitutivo de cohecho, en el sentido de la correspondiente sub-variante típica del art. 248 del $\mathrm{CP}^{16}$, sólo puede ser adecuadamente explicado si se abandona el compromiso teórico con el modelo del contrato sinalagmático.

La clave, a este respecto, aparece con la explicación de por qué, a pesar de que una interpretación del comportamiento de $\mathrm{P}$ como una propuesta bicondicional en el sentido ya precisado lleve a su caracterización como la formulación de una amenaza condicional, ese mismo comportamiento habría de ser entendido, desde el punto de vista de la tipificación del

15 Véase Mañalich, Juan Pablo, El chantaje..., cit. (n. 14).

${ }^{16}$ Cabe hacer explícito que, en tal caso, habría que reconocer la existencia de un concurso ideal entre el cohecho y el correspondiente delito de amenaza condicional, en razón de la plena independencia del contenido de injusto que exhibe cada una de esas dos especies de hecho punible frente a la otra. 
género delictivo del cohecho de funcionario público, como una instancia de realización de la específica variante típica del art. 248. Pues nótese que, bajo la interpretación de su acto de habla como una propuesta implícitamente bicondicional, $\mathrm{P}$ aparece presentando a $\mathrm{E}$ la disyuntiva de ejecutar o no ejecutar una acción cuya ejecución le es obligatoria. Y esto podría sustentar la hipótesis de que, de verse realizada alguna variante típica de cohecho por esa vía, la variante en cuestión habría de ser la establecida en el (inc. $1^{\circ}$ del) art. 248 bis del CP, en razón de que, bajo esa misma interpretación de su comportamiento, P aparece anunciando la omisión de un acto debido propio de su cargo, a saber, la omisión de la acción consistente en calificar el examen de E con la nota que objetivamente le corresponde. Pero es claro que, desde el punto de vista de la ratio subyacente a la tipificación del cohecho $-\mathrm{y}$, correlativamente, del soborno-, la propuesta que $\mathrm{P}$ dirige a $\mathrm{E}$ debe ser entendida como meramente referida a su ejecución de la acción consistente en calificar el examen de E con la nota debida, esto es, a (nada más que) la ejecución de un acto propio de su cargo. Pues es la ejecución de esa acción lo que, presumiblemente, satisface las preferencias de $\mathrm{E}$, de manera tal que para $\mathrm{E}$ pueda ser racional "remunerar" a $P$ por su ejecución.

Lo anterior hace reconocible que un modelo teórico adecuado para la reconstrucción de todas las variantes típicas de cohecho necesita poder dar cuenta de la relación "causalmente" asimétrica en que han de encontrarse el beneficio que el funcionario solicita o acepta recibir, por un lado, y el servicio funcionarial cuya eventual remuneración prospectiva o retrospectiva confiere relevancia típica a la solicitud o la aceptación de aquél, por otro. Un modelo capaz de satisfacer este requerimiento es el que aquí se presentará como el modelo de la donación remuneratoria. De acuerdo con éste, el comportamiento del funcionario, consistente en solicitar o aceptar recibir un determinado beneficio por su materialización futura o pretérita del respectivo servicio funcionarial, no necesita poder ser interpretado, sub specie cohecho, en el sentido de la formulación de una oferta condicional, sino sólo como la propuesta o la aceptación de una propuesta de celebrar, con el potencial sobornador, una donación remuneratoria. Como es obvio, el recurso a esta última noción no deja de ser metafórico. El punto es que se trata de una metáfora explicativamente más poderosa que aquella implicada en el recurso a la noción de contrato sinalagmático.

Para proveernos de una definición preliminar del concepto de donación remuneratoria, no parece haber una vía más promisoria que la de tener a la vista la definición plasmada en el art. 1433 del Código Civil, que reza: "Se entenderán por donaciones remuneratorias las que expresamente se hicieren en remuneración de servicios específicos, siempre que éstos sean de los 
que suelen pagarse"l7. Como se mostrará en lo que sigue, la noción aquí (metafóricamente) relevante de donación remuneratoria puede perfilarse reteniendo algunos y modificando otros de los componentes de la definición legal recién reproducida.

El hecho de que una donación en todo caso tenga, en el sentido aquí relevante ${ }^{18}$, el estatus de un acto bilateral, se adecua al hecho de que el comportamiento eventualmente constitutivo de cohecho pueda ser entendido como consistente en la preparación de una convención (ilícita). Tratándose en general de una donación, lo distintivo de la convención en cuestión es que ella surta o bien un efecto real, o bien, un efecto obligacional, dependiendo de si de la donación en cuestión se predica la estructura de una operación real, o bien, de una operación obligacional ${ }^{19}$. Aquí basta con observar que ambos esquemas conceptuales son pertinentes, alternativamente, para la reconstrucción típica del cohecho en cuanto delito consistente en la propuesta o la aceptación de una donación remuneratoria. Bajo el esquema de la donación como operación real, el funcionario que solicita o acepta recibir un beneficio económico por su futura o pretérita realización del respectivo servicio funcionarial aparece proponiendo al, o aceptando del, potencial sobornador que éste le transfiera aquello en lo cual consiste el beneficio en cuestión; en este sentido, el comportamiento del funcionario se presenta -hablando metafóricamente- como la propuesta o la aceptación de un negocio real, consistente en la transferencia del objeto en tal medida donado, y que no resulta constitutivo de un (pseudo-) contrato. Bajo el esquema de la donación como operación generativa de una obligación, el funcionario aparece proponiendo al, o aceptando del,

$17 \mathrm{Al}$ respecto véase sólo GuZMán Brito, Alejandro, De las donaciones entre vivos. Conceptos y tipos (Santiago, LexisNexis, 2005), pp. 237 ss.

18 Acerca de la ambigüedad sistemáticamente exhibida por el (uso jurídico del) término "donación", véase por ejemplo GuzMán Brito, Alejandro, De las donaciones..., cit. (n. 17), pp. 19 ss., quien observa que, en el contexto del Código Civil chileno, la expresión es usada a veces para designar el acto bilateral en el que consiste la donación, a veces para designar la oferta de celebrar una donación por parte del eventual donante, a veces para designar el objeto del acto bilateral en cuestión, y a veces para designar el "efecto donatorio" operado a través del respectivo acto bilateral.

19 Fundamental Guzmán Brito, Alejandro, De las donaciones..., cit. (n. 17), pp. 97 ss., 101 ss., 107 ss., 115 ss., 125 ss., dando cuenta de cómo, bajo el Código Civil chileno, coexistirían ambas formas de donación, quedando la primera plasmada en la definición general establecida en su art. 1386, según la cual la donación sería "un acto por el cual una persona transfiere gratuita e irrevocablemente una parte de sus bienes a otra persona, que la acepta”, en tanto que la segunda encontraría reconocimiento en algunas disposiciones heterogéneas, entre las cuales figuran los arts. 1402, 1417 y 2278. 
potencial sobornador que éste se comprometa a proveerle el beneficio a título de remuneración; en este sentido, el comportamiento del funcionario se presenta -hablando asimismo metafóricamente-como la propuesta o la aceptación de celebrar, con el potencial sobornador, un (pesudo-)contrato unilateral, que en tal medida sólo generaría una obligación para el segundo en cuanto donante.

Bajo cualquiera de los dos esquemas conceptuales recién contrastados se logra explicar adecuadamente el hecho de que, en los términos del acuerdo ilícito a cuya eventual celebración se orienta el comportamiento constitutivo de cohecho, sea sólo el beneficio solicitado o aceptado por el funcionario lo que debe tener como "causa" la realización pretérita o futura del respectivo servicio funcionarial, sin que, al revés, ésta hubiera de tener como "causa" el beneficio en cuestión. La clave para ello está en la caracterización de la donación a cuya celebración se orienta el comportamiento del funcionario como una de naturaleza remunera to ria, esto es, como una donación desprovista del carácter de una (pura) liberalidad. Pues en estos términos, el beneficio que el funcionario solicita o acepta recibir puede ser entendido, sin distorsión alguna, como una remuneración solicitada o aceptada por la realización futura o pretérita del respectivo servicio funcionarial, siendo éste un servicio cuya realización "no [da] acción contra la persona servida" ${ }^{20}$, esto es, que no obliga al potencial sobornador a efectuar la remuneración en cuestión, que precisamente por ello tendrá, en caso de tener lugar, el estatus de una donación.

En comparación con el modelo del contrato sinalagmático, el modelo de la donación remuneratoria logra explicar ópticamente, además, el dato regulativo consistente en la estructuración dualista de las variantes de cohecho tipificada en los arts. 248 y 248 bis del CP, en el sentido de que bajo una y otra disposición resultan subsumibles no sólo las correspondientes modalidades de cohecho antecedente sino también las de cohecho subsiguiente. Pues la noción misma de remuneración es compatible con que el funcionario proponga o solicite ser remunerado por vía de la correspondiente donación ya con anterioridad, ya con posterioridad, a la materialización del correspondiente servicio funcionarial por su parte.

No está de más constatar aquí que tal estructuración dualista de la respectiva tipificación se quiebra bajo el art. 249, que tipifica aquella variante de cohecho tratándose de la cual el servicio funcionarial ha de consistir en la perpetración de un hecho punible tipificado o bien en el párr. $4^{\circ} \mathrm{del}$

${ }^{20}$ Véase Guzmán Brito, Alejandro, De las donaciones..., cit. (n. 17), p. 237, dando cuenta de cómo la referida cláusula del art. 1738 del Código Civil admite ser generalizada como indicativa de un aspecto definitorio de toda donación remuneratoria. 
Título III o bien en el Título V del Libro II del CP. El quiebre se produce porque, a diferencia de lo que prevén los dos artículos inmediatamente precedentes, el art. 249 sólo tematiza la solicitud o la aceptación de un beneficio como remuneración por la perpetración futura de un hecho punible de alguna de las especies ya indicadas. Baste aquí con apuntar que ello no da lugar a vacío de punibilidad alguno ${ }^{21}$, en la medida en que a la solicitud o la aceptación de un beneficio por la previa perpetración de un hecho punible de alguna de esas mismas especies subyacerá, según si el delito en cuestión tiene carácter comisivo u omisivo, la solicitud o la aceptación de un beneficio, o bien, por la previa omisión de "un acto debido propio de su cargo"22, o bien, por la previa ejecución de "un acto con infracción de los deberes de cargo", en los términos del art. 248 bis $^{23}$.

Según ya se anticipara, para ofrecer una reconstrucción de la estructura típica de las diferentes variantes de cohecho punible sobre la base del modelo de la donación remuneratoria es necesario introducir algunas modificaciones a la definición plasmada en el art. 1433 del CC. Estas modificaciones son dos. La primera de ellas afecta a la cláusula según la cual una donación remuneratoria es una que se hace por servicios específicos, "siempre que éstos sean de los que suelen pagarse". Que esta exigencia resulta impertinente en la reconstrucción de la estructura típica del cohecho se sigue del hecho obvio de que, bajo el régimen jurídico que lo vincula en el desempeño de su cargo o función, el servicio funcionarial por el cual el funcionario solicita o acepta ser "remunerado" es uno que no debería dar lugar a semejante remuneración. Pues precisamente en esto descansa la relevancia delictiva de la solicitud o la aceptación del beneficio en cuestión. En tal medida, la cláusula sociológicamente orientada del art. 1433, que hace depender la atribución de carácter remuneratorio al respectivo donativo de la existencia de una práctica consuetudinaria, tiene que ser aquí substituida por la consideración normativa de que la donación propuesta o aceptada como remuneración por la realización pretérita o

${ }^{21}$ Así empero Oliver, Guillermo, Aproximación..., cit. (n. 5), p. 105.

${ }^{22}$ Véase Etcheberry, Alfredo, Derecho Penal. Parte Especial ( $3^{a}$ edición, Santiago, Editorial Jurídica de Chile, 1998), IV, p. 255.

${ }^{23}$ Véase en este sentido, aunque algo dubitativamente, RodríGUEz, Luis - OsSAndón, María Magdalena, Delitos contra la función pública (2a edición, Santiago, Editorial Jurídica de Chile, 2008), pp. 344 ss. El punto no admite discusión una vez que se advierte -como previamente ellos lo hacen (Rodríguez, Luis - Ossandón, María Magdalena, cit. (n. 23), pp. 340 ss.)- que, tratándose de la solicitud o la aceptación de un beneficio para la perpetración de un hecho punible de alguna de las especies relevantes, necesariamente se daría un concurso aparente entre la variante del art. 248 bis y la del art. 249, lo cual implica asumir que, por definición, la perpetración de tal hecho punible conlleva una "infracción de deberes del cargo". 
futura del correspondiente servicio funcionarial resulta delictiva incluso cuando éste sea de "los que suelen pagarse" 24 .

La segunda modificación, igualmente determinante, concierne a la exigencia de que la donación en cuestión sea "expresamente [hecha] en remuneración" del respectivo servicio, pues esto no se adecua al hecho de que la solicitud o la aceptación del beneficio, por parte del funcionario, pueda exhibir -y desde un punto de vista criminológico: no infrecuentemente exhiba- el carácter de una acción concluyente. Esto quiere decir, más precisamente, que la solicitud o aceptación del beneficio como remuneración por el servicio funcionarial puede, pero no necesita, ser explícita, pudiendo tener lugar, asimismo, a través de actos, verbales o no, que la hagan reconocible para su respectivo destinatario ${ }^{25}$, en atención a las circunstancias particulares que conforman el contexto de la correspondiente interacción. Lo determinante tendría que ser, en tal medida, que el funcionario se muestre "venal", en referencia al servicio funcionarial de que se trate, a través de la manifestación -verbal o no- de la correspondiente solicitud o aceptación del beneficio ${ }^{26}$.

Introducidas estas dos precisiones, el modelo de la donación remuneratoria resulta enteramente adecuado para ofrecer claves de solución dogmáticamente bien fundamentadas para varios de los problemas más intrincados que se suscitan a propósito de la reconstrucción de las variantes típicas de cohecho previstas por la regulación vigente. A ello se dedicarán las secciones siguientes del presente trabajo. Para cerrar la presente sección, no estaría de más hacer explícito que la sustitución del modelo del contrato bilateral por el modelo de la donación remuneratoria conlleva, en atención a la naturaleza jurídica que exhibe una donación, una redefinición de la metáfora contractual como una metáfora (sólo) "convencional”.

\section{LA CONEXIÓN ENTRE EL SERVICIO FUNCIONARIAL Y EL ÁMBITO}

\section{COMPETENCIAL DEL FUNCIONARIO}

Ya se ha hecho una referencia preliminar a la diferente manera en que los arts. 248, 248 bis y 249 del CP especifican en qué ha de consistir el servicio funcionarial por o para cuya realización el funcionario solicita o acepta el beneficio correspondiente a modo de "remuneración". Ahora es

${ }^{24}$ Pues lo contrario llevaría a convertir la eventual generalización de las correspondientes muestras de corrupción en una causa de atipicidad sub specie cohecho (y soborno).

${ }^{25}$ Kuhlen, Lothar, cit. (n. 10), $\$ 331$, n.m. 20, 24.

${ }^{26}$ Véase Kuhlen, Lothar, cit. (n.10), $\$ 331$, n.m. 22. 
necesario indagar con mayor precisión en el alcance de las formulaciones plasmadas en los arts. 248 y 248 bis.

Si bien es usual que la variante de cohecho tipificada en el art. 248 sea denominada "básica" 27 , o "simple"28, la corrección de esta designación depende de la relación sistemática en que ella se encuentre con la variante del art. 248 bis. En la medida en que esta última disposición tipifica una variante de cohecho que integra una sub-variante consistente en la solicitud o la aceptación de un beneficio por o para la o misión de un "acto debido propio de su cargo", es claro que la variante del art. 248 no se comporta como "básica" o "simple", dado que bajo este artículo sólo tiene relevancia típica la aceptación o solicitud de un beneficio por o para la ejecución de algún acto (propio del cargo). Por ello, y a diferencia de lo que sucede entre las variantes de los arts. 248 bis y 249 , la segunda de las cuales constituye -según ya se sostuviera- una especificación de la primera, dándose entre ambas una relación de inclusión (o subordinación), entre las variantes del art. 248 y del art. 248 bis existe, más bien, una relación de interferencia (o superposición parcial) ${ }^{29}$.

La falta de identidad entre los presupuestos típicos de una y otra variante de cohecho se deja advertir incluso si se prescinde de aquella sub-variante típica del art. 248 bis, ya mencionada, que se distingue por el carácter omisivo del servicio funcionarial en razón del cual el funcionario solicita o acepta ser remunerado a través de la correspondiente "donación". Pues aun restringiendo el análisis a los casos en que el servicio funcionarial consiste en la ejecución de un cierto acto, hay buenas razones para poner en duda que la realización de la correspondiente sub-variante típica del art. 248 bis necesariamente conlleve la realización de la variante típica del art. 248. Pues no es en absoluto evidente que la ejecución de "un acto con infracción a los deberes del cargo", en los términos del art. 248 bis, necesariamente entrañe la ejecución, por parte del funcionario respectivo, de "un acto propio de su cargo", en los términos del art. 248.

Para la definición del alcance de la expresión "acto propio de su cargo", la doctrina suele contrastar dos posibilidades, respectivamente consistentes en una interpretación "extensiva" y en una "restrictiva" ${ }^{30}$. Bajo la

27 Así Oliver, Guillermo, Aproximación..., cit. (n. 5), pp. 96, 101; Rodríguez, Luis - Ossandón, María Magdalena, cit. (n. 23), pp. 331, 339.

${ }^{28}$ Garrido, Mario, Derecho Penal. Parte Especial (4a edición, Santiago, Editorial Jurídica de Chile, 2010), III, p. 465.

${ }^{29}$ Véase al respecto MañAlich, Juan Pablo, Estudios sobre la fundamentación y la determinación de la pena (Santiago, Thomson Reuters, 2018), pp. 185 ss., 195 ss., con referencias ulteriores.

${ }^{30}$ Véase Oliver, Guillermo, Aproximación..., cit. (n. 5), pp. 100 ss.; Rodrí- 
primera interpretación, por "acto propio del cargo" cabría entender todo aquel que "guarde (...)relación con las actividades públicas que éste realiza", pudiendo ejecutarlo "con facilidad por la función que desempeña, pero sin que su ejecución corresponda específicamente al ámbito de su competencia" 31 . Bajo la segunda, en cambio, sólo cabría entender por tal un acto "cuya realización obedece al ejercicio de las funciones públicas", en cuanto radicado en el ámbito competencial del funcionario en cuestión ${ }^{32}$.

Es ciertamente plausible asumir que esta última solución es la mejor aspectada tratándose, en efecto, de la interpretación de la cláusula contenida en el art. 248. Esto no equivale a sostener, como recientemente ha sugerido Oliver, que el ámbito de los actos propios del cargo pueda quedar condicionado por las decisiones de distribución interna de tareas adoptadas al interior de la repartición pública en la que se desempeña el funcionario respectivo ${ }^{33}$. Antes bien, es suficiente que se trate de actos que muestren una conexión funcional con su ámbito de competencia, tal como ello es favorecido por la doctrina y la jurisprudencia alemanas, sin que ello resulte alterado por decisiones de distribución interna de tareas ${ }^{34}$.

Hay que observar, adicionalmente, que Oliver mismo advierte que hay deberes que recaerían sobre todo funcionario público sin que ello obste a que, al darles cumplimiento, el respectivo funcionario efectivamente aparezca obrando "dentro de su competencia". El ejemplo ofrecido es el del deber de todo empleado público de denunciar los hechos punibles de los cuales tomaran conocimiento en el ejercicio de sus funciones, establecido en la letra b) del art. 175 del Código Procesal Penal ${ }^{35}$. Reconocer que el cumplimiento de semejante deber se corresponde con un acto propio del cargo de cada funcionario es indispensable para dar sentido a la idea de que el incumplimiento de ese deber se corresponderá -como tendría que ser obvio- con la omisión de "un acto debido propio del cargo", de manera tal que la solicitud o la aceptación de un beneficio por la omisión futura o pretérita de ese acto pueda resultar constitutiva de cohecho bajo el inc. $1^{\circ}$ del art. 248 bis del CP.

Guez, Luis - Ossandón, María Magdalena, cit. (n. 23), pp. 337 ss.

${ }^{31}$ Oliver, Guillermo, Aproximación..., cit. (n. 5), p. 101.

32 Oliver, Guillermo, Aproximación..., cit. (n. 5), p. 100.

33 Oliver, Guillermo, ¿Atipicidad del cohecho de empleado público para infringir deberes funcionariales genéricos?, en CÁrdenas, Claudia - Ferdman, Jorge (coords.), El derecho penal como teoría y como práctica. Libro en Homenaje a Alfredo Etcheberry Orthusteguy (Santiago, Thomson Reuters, 2016), pp. 809 ss.

34 Véase Kuhlen, Lothar, cit. (n. 10), \$331, n.m. 66 ss.; KindhäUser, Urs, cit. (n. 10), $\$ 331$, n.m. 10.

${ }^{35}$ Véase Oliver, Guillermo, Atipicidad..., cit. (n. 33), pp. 810, 812. 
Con independencia de lo anterior, tendría que ser igualmente claro, como también ha sostenido Oliver, que esa misma solución restrictiva no puede ser correcta tratándose de la interpretación de la cláusula "con infracción a los deberes de su cargo", en el contexto de la tipificación de la segunda sub-variante de cohecho prevista en el art. $248 \mathrm{bis}^{36}$. Pues ésta no exige que el acto para o por cuya ejecución el funcionario solicita o acepta el respectivo beneficio sea "propio del cargo"; antes bien, la cláusula sólo exige que la ejecución del acto tenga lugar "con infracción a los deberes del cargo". En contra de lo sostenido por la Corte Suprema en su fallo recaído en causa rol No 2560-13, de 13 de junio de $2013^{37}$, es crucial advertir que como "deberes del cargo" también vienen en consideración aquellos deberes "genéricos" que recaen sobre el funcionario público por el solo hecho de desempeñarse como tal.

La demostración más palmaria de lo anterior la ofrece, sin ir más lejos, el propio inc. $2^{\circ}$ del mismo art. 248 bis, que cualifica la variante de cohecho aquí prevista, asociándole la pena de inhabilitación absoluta perpetua para cargo u oficio público, reconociendo explícitamente la posibilidad de que "la infracción al deber del cargo consistiere en ejercer influencia en otro empleado público con el fin de obtener de éste una decisión que pueda generar un provecho para un tercero interesado". Es suficientemente obvio que el deber infringido a través de semejante ejercicio de influencia en otro funcionario público ${ }^{38}$, por definición, no es un deber específicamente determinado por el ámbito competencial de desempeño del funcionario, sino uno genéricamente impuesto a través del sometimiento del ejercicio de todo cargo público a determinados estándares de probidad. Esto muestra, entonces, que es típicamente relevante a título de cohecho, bajo el art. 248 bis, la solicitud o la aceptación de un beneficio, por parte de un funcionario público, como remuneración por la ejecución (pretérita o futura) de un acto a través del cual se infringen "deberes de su cargo", sea que éstos le estén impuestos en razón de su específico ámbito de competencia, sea que le estén impuestos en razón de su condición de funcionario público.

${ }^{36}$ Véase Oliver, Guillermo, Atipicidad..., cit. (n. 33), pp. 809 ss.

37 Coincidentemente Artaza, Osvaldo, cit. (n. 1), pp. 325 ss.

${ }^{38}$ Ejercicio de influencia que, como bien observa Oliver, Guillermo, Aproximación..., cit. (n. 5), p. 104, no necesariamente será constitutivo del delito de tráfico de influencia tipificado en el art. 240 bis del CP, en la medida en que la realización del tipo del tráfico de influencia exige que sea la propia persona del funcionario, una persona (directa o indirectamente) relacionada con éste de determinada manera, o bien, una persona jurídica o empresa en la cual alguna de las personas anteriores tenga una determinada participación, la que tenga interés en la decisión para cuya adopción aquél ejerza influencia en otro funcionario. 


\section{LA EXIGENCIA TÍPICA DE DETERMINACIÓN DEL SERVICIO FUNCIONARIAL}

Un segundo problema cuya solución es imprescindible para esclarecer los contornos típicos de las diferentes variantes de cohecho consiste en precisar el nivel de determinación con que tiene que resultar especificado el correspondiente servicio funcionarial en el contexto de la "convención donatoria" a cuya celebración se orienta el comportamiento típicamente relevante del funcionario. Nuevamente circunscribiendo el análisis a los arts. 248 y 248 bis, ya se ha establecido que el servicio funcionarial, para o por cuya realización el funcionario ha de solicitar o aceptar el respectivo beneficio, tiene que consistir, o bien, en la ejecución de algún acto propio del cargo, o bien en la omisión de un acto debido propio de su cargo, o bien en la ejecución de un acto con infracción de los deberes del cargo. Esto basta para concluir que la regulación hoy vigente no hace punible el así llamado cohecho "por la función" o "por el ejercicio del cargo"39, que precisamente se distingue por el hecho de que la remuneración que el funcionario solicita o acepta recibir no se encuentra referida a la realización de un "servicio específico", en los términos de la definición del art. 1433 del CC, sino más bien al genérico desempeño del cargo o función como tal.

Las implicaciones de esta caracterización de la situación jurídica vigente se vuelven más claras si se tienen a la vista algunos antecedentes de derecho comparado. En efecto, tanto el derecho alemán como el derecho español hoy vigentes conocen variantes suficientemente próximas a tal cohecho "por la función" " "por el ejercicio del cargo ${ }^{\text {"40. }}$. A partir de la reforma introducida por ley de 13 de agosto de 1997 , el apartado $1^{\circ}$ del $\$ 331$ del StGB tipifica la así llamada "aceptación de ventaja" (Vorteilsannahme) como un delito consistente en exigir, dejarse prometer o recibir una ventaja, por parte de un funcionario público, "por el desempeño del servicio" (für die Dienstausübung). Respecto de este delito, entonces, el cohecho (Bestechlichkeit), tipificado en el $\$ 332$ del StGB y consistente en exigir, dejarse prometer o recibir una ventaja, por parte de un funcionario público, "como contraprestación por el hecho de haber ejecutado o ejecutar futuramente una acción del servicio y por esa vía haber infringido o llegar a infringir sus deberes de servicio", se constituye como una forma calificada ${ }^{41}$. Esta modificación es doctrinalmente explicada en el sentido de un debilitamiento, pero no de una supresión, de la exigencia de que el comportamiento del funcionario

39 En detalle al respecto Hernández, Héctor, cit. (n. 9), pp. 17 ss.

${ }^{40}$ Para más antecedentes de derecho comparado, véase Hernández, Héctor, cit. (n. 9), pp. 23 ss.

${ }^{41}$ KindhäUSER, Urs, $L P K-S t G B$, cit. (n. 10), $₫ 332$, n.m. 1. 
se oriente a la celebración de un pacto ilícito, en términos tales que sería el genérico desempeño de la función, como tal, aquello por lo cual la ventaja respectiva es exigida, aceptada o recibida como contraprestación ${ }^{42}$. Con aun mayor laxitud, por su parte, el art. 422 del Código Penal español, y en congruencia con una larga tradición de la codificación hispánica ${ }^{43}$, hace punible la admisión, "por sí o por persona interpuesta", por parte de una autoridad o un funcionario público, de "dádiva o regalo que le fueren ofrecidos en consideración a su cargo of función" $" 44$.

Sobre este trasfondo, es indiscutible que los arts. 248 y 248 bis exigen que el funcionario solicite o acepte el beneficio (económico) para realizar o por haber realizado un comportamiento determinado, constitutivo del respectivo "servicio funcionarial" en el sentido ya precisado. Pero esto ciertamente no basta para zanjar el grado de determinación con que debe aparecer especificado el acto de cuya ejecución u omisión, pasada o futura, por parte del funcionario público se trata. A este respecto, es particularmente importante tomar nota de la manera en que la jurisprudencia alemana planteaba el problema a propósito de la regulación vigente con anterioridad a la ya referida modificación legislativa del año 1997.

Ya en su relevante fallo pronunciado el 29 de febrero de $1984^{45}$, el Tribunal Supremo Federal alemán (en adelante “el BGH”) llamó explícitamente la atención sobre lo improcedente de sujetar la determinación de la respectiva "acción de servicio" (Diensthandlung) a exigencias de precisión demasiado elevadas, pues lo contrario llevaría a privilegiar a aquellos funcionarios públicos "que se muestran venales no sólo respecto de una concreta acción de servicio singular, sino para ámbitos vastos de su quehacer". A esto se añade, agregaba el BGH, que los involucrados "muchas veces no tienen representación precisa alguna acerca de cuándo, en qué oportunidad, y de qué manera el funcionario debería dar cumplimiento al pacto ilícito, pues las acciones de servicio singulares, correspondientes a ello, frecuentemente no se dejan determinar con antelación".

${ }^{42}$ Kuhlen, Lothar, cit. (n. 10), $\$ 331$, n.m. 4, 19, 80.

43 Véase Rodríguez Devesa, José María, Derecho Penal Español. Parte Especial (14a edición, Madrid, Dykinson, 1991), pp. 1171 ss. Una muestra del impacto de esa tradición la ofrece, por ejemplo, el Código Penal argentino, cuyo actual art. 259 tipifica el comportamiento del funcionario público consistente en admitir "dádivas, que fueran entregadas en consideración a su oficio, mientras permanezca en el ejercicio del cargo".

${ }_{44} \mathrm{Al}$ respecto Ortiz de Urbina, Ińigo, Delitos contra la administración pública, en Silva Sánchez, Jesús María (dir.) - Ragués, Ramón (coord.), Lecciones de Derecho Penal. Parte Especial (4a edición, Barcelona, Atelier, 2015), pp. 368 ss.

${ }_{45}$ BGH 2 StR 560/83. Al respecto KuHLEN, Lothar, cit. (n. 10), \$ 331, n.m. 75 ss. 
De ahí que, según el BGH, no pudiera "exigirse que la acción de servicio, que constituye el objeto del pacto ilícito, esté ya fijada en su configuración concreta según tiempo, ocasión y forma de ejecución, en todas sus particularidades". Antes bien, sería suficiente que "el acuerdo de los involucrados se encuentre referido a que el funcionario público, al interior de un determinado ámbito de tareas (...) deba activarse en una cierta dirección”, en términos tales que la acción de servicio en cuestión esté establecida y sea "reconocible según su contenido material a lo menos en lineamientos gruesos", de manera tal que sea reconocible "en qué dirección" ha actuado o habrá de actuar aquél ${ }^{46}$. Un posterior pronunciamiento del propio BGH estimó suficiente, en ese mismo sentido, que un funcionario del ejército, con competencia para realizar adquisiciones, prometiese a un distribuidor de alimentos "considerarlo más fuertemente en el futuro ante demandas de pedidos ${ }^{\text {'477. }}$. E igualmente importante resulta ser un fallo, pronunciado por el BGH con fecha 23 de octubre de $2002^{48}$, en referencia a sucesos que habían tenido lugar antes de la reforma del año 1997. Reiterando su desestimación de la tendencia a someter la identificación de la correspondiente acción de servicio a exigencias de determinación excesivas, sostuvo el BGH que es suficiente que quienes han de dar y recibir la ventaja "estén de acuerdo acerca del tipo del servicio remunerado, también si ellos no tienen representación precisa alguna acerca de cuándo, en qué oportunidad y de qué manera el funcionario público quiera dar cumplimiento al acuerdo".

La solución favorecida por la jurisprudencia del BGH es fácil de compatibilizar con el punto de partida representado por el modelo de la donación remuneratoria. Pues la relativa indeterminación que, de acuerdo con el BGH, puede exhibir el servicio funcionarial por el cual el funcionario solicita o acepta ser "donatoriamente remunerado" es congruente con la relatividad-a-la-contingencia que puede exhibir, característicamente, el servicio por cuya prestación alguien resulta remunerado. En este sentido, el modelo de la donación remuneratoria exhibe, frente al modelo del contrato sinalagmático, la ventaja de resultar considerablemente más adaptable a las particularidades de cada uno de los contextos regulativos en los cuales puede resultar aplicable. Esto se traduce, específicamente, en que desde el punto de vista provisto por el modelo de la donación remuneratoria, la diferencia entre la estructura típica del cohecho referido a la ejecución o la omisión de acto vinculado al desempeño del cargo o la función -esto es, del cohecho "de servicio"-, tal como aquel se encuentra excluyentemente

\footnotetext{
${ }^{46}$ Kuhlen, Lothar, cit. (n. 10), $\$ 331$, n.m. 76.

${ }^{47}$ Kunlen, Lothar, cit. (n. 10), $\$ 331$, n.m. 76.

${ }^{48}$ BGH 1 StR 541/01.
} 
previsto por el derecho chileno vigente, y la estructura típica del cohecho "por la función", cuya criminalización pudiera resultar de una modificación del derecho vigente, se presente como una diferencia de grado, a saber, precisamente por la gradualidad con la que puede verse incrementado o reducido el nivel de precisión del objeto de la remuneración solicitada o aceptada por el funcionario ${ }^{49}$.

Desde luego, lo anterior ciertamente no sirve para superar un sensible vacío de punibilidad, que como tal sólo es corregible de lege ferenda, como si se tratase de un problema reducible a la adecuada reconstrucción dogmática de la lex lata. Pero sí sirve para hacer reconocible la elevadísima proximidad estructural que exhiben una y otra forma de cohecho, que precisamente por esa razón admiten ser entendidas, sistemáticamente, como especificaciones de un mismo concepto. El modelo de la donación remuneratoria hace identificable, más allá de las denominaciones legislativas que vengan en consideración, la unidad estructural exhibida por las variadas especies y sub-especies de cohecho eventualmente punible.

\section{El PROBLEMA DE LAS “RELACIONES REMUNERATORIAS” TEMPORALMENTE EXTENDIDAS}

Sentado lo anterior, cabe examinar ahora el problema relativo a las condiciones bajo las cuales puede tenerse por comprobada la referencia del acuerdo buscado o alcanzado por el funcionario público a la ejecución u omisión de un acto conectado con el desempeño de la función o el cargo, y por la cual habría de tener lugar el "donativo remuneratorio" en cuestión, en casos en los cuales la solicitud o la aceptación de éste asume la forma de un comportamiento concluyente. Una consideración especialmente sugerente del problema aparece en la sentencia del BGH de 19 de octubre de $1999^{50}$, referida a un caso en el cual, bajo la regulación introducida a través de la reforma de 1997, el funcionario acusado había sido condenado, entre otros, por quince delitos de aceptación de ventaja (y no de cohecho), en razón de que, supuestamente, sólo había sido posible establecer que las regalías en cuestión habían sido recibidas por el desempeño del cargo,

49 Valga la precisión de que de ello no se sigue sin más que, bajo un régimen regulativo que tipifique tanto el cohecho "por la función" como el cohecho "de servicio”, este último necesariamente debería contar, desde un punto de vista penológico, como una forma calificada del primero. Es perfectamente concebible, por ejemplo, que la regulación en cuestión pudiera reconocer criterios de graduación del injusto exhibido por una o ambas formas de cohecho que fueran sensibles, más bien, a la relevancia del cargo desempeñado.

${ }^{50}$ BGH 1 StR 264/99. 
pero no como contraprestación por la ejecución pretérita o futura de alguna acción del servicio, con infracción de los deberes del servicio. En su anulación del fallo condenatorio a este respecto, el BGH entendió que la existencia de una ya larga y consolidada relación entre el funcionario, director médico de una institución hospitalaria, y el aportante de las regalías, responsable de una firma italiana dedicada a la distribución de marcapasos, era suficiente, desde ya, para hacer reconocible un acuerdo concluyente entre ellos en cuanto a que las sucesivas y reiteradas invitaciones recibidas y aceptadas por el primero a cenar en restaurantes de lujo y a visitar (en dos ocasiones) el establecimiento de la compañía en Italia tenían lugar en la expectativa de la firma de seguir recibiendo, en el futuro, órdenes de compra de marcapasos. Pero a ello añadió el BGH que, en atención a esas mismas circunstancias, era errado que el tribunal de instancia no hubiese concluido que, al aceptar las invitaciones sucesivamente recibidas, el director del hospital había mostrado que esas invitaciones "habrían de jugar un rol en la decisión a favor de ulteriores órdenes de compra”.

Aquí es imprescindible no perder de vista que la razón esgrimida por el BGH para invalidar, en el caso recién considerado, la condena por los quince delitos de mera aceptación de ventaja (en los términos del $₫ 331$ del StGB) estuvo constituida por la plausibilidad de recalificar cada uno de los quince hechos como constitutivos de cohecho (en los términos del $\$ 332$ del StGB), precisamente en atención a la plausibilidad de tener por establecida la existencia de una puesta en relación, en el sentido sinalagmáticamente relevante, de cada una de las invitaciones aceptadas por el acusado con una muestra de su parte a considerar favorablemente la emisión de órdenes de compra a favor de la firma. Pues la misma consideración de los elementos contextuales pertinentes debería valer para tener por comprobada la existencia del correspondiente pacto ilícito bajo la regulación del cohecho plasmada en el CP, allí donde la interacción entre el funcionario y su presunto sobornador se desarrolla, de manera más o menos consistente, a lo largo de un lapso más o menos prolongado.

Hernández ha advertido acerca de algunas de las dificultades probatorias que trae consigo el modelo regulativo aún vigente en Chile, que justamente se distingue por la falta de tipificación del cohecho "por la función" o "por el ejercicio del cargo", el diagnóstico de lo cual ha tenido una importancia considerable en el debate legislativo más reciente ${ }^{51}$. El modelo regulativo todavía vigente vuelve necesario que se compruebe judicialmente, más allá

${ }^{51}$ Se trata de la discusión del proyecto de ley correspondiente al boletín № 10739-07, iniciado por moción de los senadores Araya, De Urresti, Espina, Harboe y Larraín. 
de toda duda razonable, "no sólo que ha habido determinadas manifestaciones de voluntad (por parte de un empleado público, de un particular, o de ambos) en relación con un posible pago a un empleado público, sino además que ese pago representaba la contraprestación al menos potencial por un determinado acto de servicio, pasado o futuro, por parte del funcionario en cuestión" 52 .

Mas inmediatamente después de dar cuenta de esta dificultad probatoria, Hernández observa lo siguiente: "Sin duda habrá muchos casos en que, sobre la base de indicios, no será difícil tener por acreditada la conexión entre el pago y un determinado acto de servicio, por una parte, porque no resulta plausible que el pago efectuado pudiera haber tenido una motivación independiente, distinta de la calidad que ostentaba el sujeto que lo recibió, y por la otra, lo que será decisivo, porque no resulta plausible que el pago hecho en razón del cargo del sujeto no haya sido, además, la contraprestación por un acto determinado de servicio, lo que puede colegirse, por ejemplo, de la circunstancia de que el acto en cuestión es muy relevante para los intereses de quien efectúa el pago, que se trata de un acto más o menos extraordinario, que el interesado no tiene el derecho a que el acto se dé necesariamente en el sentido en que se dio y que lo probable era más bien lo contrario, que el rol del funcionario en ese acto es más o menos determinante, etc." ${ }^{\text {‘3 }}$.

Esto muestra que la insoslayable constatación de que el Código Penal chileno no tipifica, al día de hoy, alguna forma de cohecho "por la función" o "por el ejercicio del cargo" no excluye en lo absoluto la posibilidad de tener por realizada una o más variantes típicas de cohecho, en los términos de los arts. 248 y siguientes del CP, tratándose de casos que involucran alguna interacción sostenida en el tiempo entre el funcionario y quien pudiera fungir, a su respecto, como eventual sobornador. En estos términos, la comprobación procesal de la realización del tipo del cohecho dependerá de que, en atención a las particularidades de esa misma interacción, sean reconocibles indicios de que el beneficio solicitado o aceptado por el primero adquiere, en el marco de esa misma interacción, el sentido de una "remuneración" por la realización, pasada o futura, de algún servicio funcionarial.

52 Hernández, Héctor, cit. (n. 9), p. 21.

${ }^{53}$ Hernández, Héctor, cit. (n. 9), p. 22. 
Un rasgo ineludible del modelo regulativo todavía plasmado, de lege lata, en el Código Penal chileno consiste en la naturaleza económica que ha de revestir el beneficio que el funcionario solicita o acepta como contraprestación a la realización del correspondiente servicio funcionarial ${ }^{54}$. Ello resulta indubitable en atención al solo tenor literal de los arts. 248 y siguientes, que en general especifican la remuneración por la realización del respectivo servicio funcionarial, que el funcionario ha de solicitar o aceptar, como consistente en un "beneficio económico", y no deja de serlo en atención a la posibilidad de que, bajo el art. 248 , ese beneficio pueda consistir en la percepción de "mayores derechos de los que le están señalados por razón de su cargo".

A este respecto, puede ser ilustrativo examinar el problema de si la exigencia típica de que el beneficio solicitado o aceptado por el funcionario exhiba naturaleza económica pudiera verse insatisfecha en razón de su destinación al financiamiento de una campaña política. Aquí puede ser oportuno, una vez más, tener a la vista la manera en que la jurisprudencia alemana ha reconocido la necesidad de restringir teleológicamente, por vía de interpretación restrictiva, el alcance del tipo de la ya mencionada "aceptación de ventaja”, establecido en el $\$ 331$ del StGB, en pos de resguardar el principio de igualdad de oportunidades en lo tocante a la relación entre candidatos afiliados y candidatos no afiliados a partidos políticos, desde el punto de vista de sus respectivas chances de conseguir financiamiento electoral. En un muy relevante fallo emitido el 28 de octubre de $2004^{55}$, el BGH declaró que: "un funcionario no se hace punible por aceptación de ventaja si él nuevamente se presenta al cargo de elección popular actualmente ejercido por él, y a ser obtenido como resultado de elección directa, y para su reelección solicita, se deja prometer o recibe el apoyo financiero o de otra indole de un tercero, para sí o para el partido o la asociación de electores que representa, siempre que esta exigencia sólo deba servir o sirva a que él, tras resultar electo, ejerza el cargo de una manera que se corresponda con las representaciones generales, económicas o políticas, de quien aportara la ventaja".

Pero a renglón seguido el BGH introducía, sin más, la siguiente prevención: "En cambio, si el funcionario se muestra dispuesto a adoptar o influenciar una concreta decisión a favor del aportante de la ventaja, que promueva los intereses de éste, en caso de llegar a ser elegido, como contrapartida

${ }^{54}$ Véase por todos Oliver, Guillermo, Aproximación..., cit. (n. 5), pp. 96 ss.; Rodríguez, Luis - Ossandón, María Magdalena, cit. (n. 23), pp. 332 ss.

${ }^{5}$ BGH 3 StR 301/03. 
por el donativo de campaña, entonces él se hace culpable de una aceptación de ventaja (...)".

Sobre la base de este razonamiento, es manifiesto que, presentándose como "remuneración" por la realización pasada o futura de algún servicio prestado en conexión con el cargo, el donativo consistente en el aporte financiero a una campaña electoral puede resultar sin más constitutivo de un beneficio cuya solicitud o aceptación sea, para el funcionario en cuestión, constitutiva de cohecho. Y debería estar fuera de toda discusión que ese beneficio por definición tiene carácter económico, en el sentido de la regulación legal chilena.

Cabe apuntar que, en contra de lo que pudiera creerse, la jurisprudencia de la Corte Suprema no avala la sugerencia de que semejante aporte financiero a una campaña electoral no podría exhibir el carácter de un beneficio económico bajo los arts. 248 y siguientes del CP. En su sentencia de reemplazo pronunciada con fecha 10 de mayo de $2007^{56}$, tras haber acogido un recurso de casación en la forma interpuesto en contra de la respectiva sentencia condenatoria, recaída en el así llamado "caso Coimas", la corte en efecto dio lugar a la absolución de uno de los acusados (correlativamente) por soborno, en razón de que éste "pagó no para obtener algún favor que se haya determinado en los autos, sino únicamente para financiar campañas politicas" (cons. 9०). Pero la corte concluyó lo anterior a partir de la sola desestimación de que hubiese evidencia suficiente de que los montos destinados al financiamiento de las campañas en cuestión hubieran sido traspasados existiendo, de parte de los funcionarios respectivos, "una oferta a cambio del aporte económico, consistente en realizar algún acto o incurrir en alguna omisión que favoreciere al empresario F. o algún tercero" (cons. $7^{\circ}$ ). De ahí que la decisión de la corte no haya dependido de una negación de que el aporte dinero a una campaña política pueda constituir un beneficio económico en el sentido de la tipificación del cohecho (y del soborno), sino únicamente de la detección de una insuficiencia probatoria de su vinculación "remuneratoria" con el respectivo servicio funcionarial.

${ }^{56}$ En causa rol No 3430-2005. 


\section{BiBLIOGRAFÍA}

ArTaza, Osvaldo, La utilidad del concepto de corrupción de cara a la delimitación de la conducta típica en los delitos de cohecho, en Política Criminal 11 (2016), 21.

Beling, Ernst, Die Lehre vom Verbrechen (Tubinga, J.C.B. Mohr [Paul Siebeck], 1906).

BINDING, Karl, Lehrbuch des Gemeinen Deutschen Strafrechts (Léipzig, Felix Meiner, 1905), II.

Carnevali, Raúl - ARTAZA, Osvaldo, La naturaleza pluriofensiva y transnacional del fenómeno de la corrupción. Desafios para el Derecho Penal, en Ius et Praxis 22 (2016), 2.

Carrara, Francesco, Programa de Derecho Criminal. Parte Especial (Bogotá, Temis, 1961), V.

Claro Solar, Luis, Explicaciones de derecho civil chileno y comparado (Santiago, Editorial Jurídica de Chile, 1979), V.

Etcheberry, Alfredo, Derecho Penal. Parte Especial (3a edición, Santiago, Editorial Jurídica de Chile, 1998), IV.

Garrido, Mario, Derecho Penal. Parte Especial (4a edición, Santiago, Editorial Jurídica de Chile, 2010), III.

Green, Stuart, Lying, Cheating, and Stealing (Oxford y Nueva York, Oxford University Press, 2006).

Guzmán Brito, Alejandro, Derecho Privado Romano (Santiago, Editorial Jurídica de Chile, 1996), I.

GuZmán Brito, Alejandro, De las donaciones entre vivos. Conceptos y tipos (Santiago, LexisNexis, 2005).

Guzmán Dalbora, José Luis, Colectánea Criminal. Estampas de la parte especial del derecho penal (Buenos Aires y Montevideo, BdF, 2017).

HERNÁNDEZ, Héctor, La inconveniente exigencia de un acto funcionario determinado como contraprestación en el delito de cohecho, en Revista de Ciencias Penales 43 (2016), 4, pp. 15-28.

KindHÄUser, Urs, Presupuestos de la corrupción punible en el Estado, la economía y la sociedad. Los delitos de corrupción en el Código penal alemán, en Política Criminal 2 (2007), 3, pp. 1-18.

KindHÄUSER, Urs, $L P K-S t G B$ (4a edición, Baden-Baden, Nomos, 2010).

Kindhäuser, Urs, 263, en Kindhäuser, Urs - Neumann, Ulfrid - Paeffgen, HansJörg (coords.), $N K-S t G B$ (5a edición, Baden-Baden, Nomos, 2017).

Kuhlen, Lothar, 331, en Kindhäuser, Urs - Neumann, Ulfrid - Paeffgen, Hans-Jörg (coords.), NK-StGB (5a edición, Baden-Baden, Nomos, 2017).

Labatut, Gustavo, Derecho Penal (7a edición, Santiago, Editorial Jurídica de Chile, 2005), II.

MaÑAlich, Juan Pablo, La negociación incompatible como delito de corrupción, en Revista de Estudios de la Justicia 23 (2015).

Mañalich, Juan Pablo, Estudios sobre la fundamentación y la determinación de la pena (Santiago, Thomson Reuters, 2018).

MaÑAlich, Juan Pablo, El chantaje como coacción. Una reconstrucción lógica de la distinción entre amenazas y ofertas condicionales, en DOXA 41 (2018), en prensa.

Oliver, Guillermo, Aproximación al delito de cohecho, en Revista de Estudios de la Justicia 5 (2004). 
Oliver, Guillermo, ¿Atipicidad del cohecho de empleado público para infringir deberes funcionariales genéricos?, en CÁRDENAS, Claudia - FERDMAN, Jorge (coords.), El derecho penal como teoría y como práctica. Libro en Homenaje a Alfredo Etcheberry Orthusteguy (Santiago, Thomson Reuters, 2016).

Ortiz de Urbina, Iñigo, Delitos contra la administración pública, en Silva Sánchez, Jesús María (dir.) - Ragués, Ramón (coord.), Lecciones de Derecho Penal. Parte Especial (4a edición, Barcelona, Atelier, 2015).

Rodríguez, Luis - Ossandón, María Magdalena , Delitos contra la función pública (2a edición, Santiago, Editorial Jurídica de Chile, 2008).

Rodríguez Devesa, José María, Derecho Penal Español. Parte Especial (14a edición, Madrid, Dykinson, 1991). 